\title{
Carroll's CSR Pyramid: An Empirical Investigation of SME CSR Orientation
}

\author{
Sophia Kusyk \\ York University
}

\begin{abstract}
The corporate social responsibility responsibly (CSR) pyramid (Carroll, 1991) plays a substantive role in business and social theory, and research on it is incomplete if it disregards the full gambit of organizational contexts. By focusing on small enterprises (SMEs), this mixed methods study makes a dual contribution to the growing body of research on Carroll's (1991) (CSR) pyramid. First, the research addresses the hierarchy of the CSR pyramid in the previously neglected context of SMEs in Spain. Second, grounded in CSR orientation (CSRO) theory (Schwartz \& Carroll, 2003), the study demonstrates how CSR dimensions differ between best practice corporate social performance (CSP) and normal CSP companies. The findings challenge the original hierarchy of the CSR dimensions and suggest that the philanthropic dimension is a differentiator for CSROs. Thus, in contrast to the original CSR pyramid (Carroll, 1991) and in line with the development of CSR orientation theory (Schwartz \& Carroll, 2003), a balanced CSRO emphasis for best practice CSP is supported.
\end{abstract}

Keywords: CSR, CSRO, SME, CSP

\section{INTRODUCTION}

Carroll's (1991) corporate social responsibility (CSR) pyramid is a prominent landmark in the landscape of CSR theories, approaches and frameworks (Calabretta et al., 2011; De Bakker et al., 2005; Google Scholar, 2021; Ma, 2009). It proposes a well-established classification of individual philosophy and enterprise actions along four areas of responsibility domains comprising of a required economic base, followed by smaller building blocks of required legal, expected ethical and desired discretionary responsibility. For over three decades, there has been a growing body of empirical evidence questioning the composition of the proposed CSR dimensions with their corresponding CSR orientation (CSRO) (Aupperle, 1984). A comprehensive review of 35 years of CSRO research (1984-2019) has shown that CSRO is context-dependent and that the original hierarchy only holds true for $30 \%$ of the studies, while the rest of the studies yielded mixed CSR pyramids (Kusyk et al., 2021). Despite scholarly attention, pieces of knowledge are still missing to complete the CSR pyramid puzzle, including the extent to which different environmental (Paul et al., 2019; Schmidt \& Cracau, 2018; Visser, 2006) and organizational contexts (Klassen, 2001; Spence, 2016) influence CSR orientation. This paper makes a significant contribution in two important areas: First, in light of the growing evidence challenging the CSR pyramid hierarchy (see Kusyk et al., 2021 for a full review), it fills an important empirical context gap by further investigating whether the CSR hierarchy is applicable in the context of small and medium-sized enterprises (SMEs). Second, this study is the first to test CSRO theory (Schwartz and Carroll, 2003) using a multi-method case 
study. Overall, this study contributes to a better understanding of the dimensions of the CSR pyramid in an underrepresented context. With the two research objectives in mind, the paper begins with a brief introduction to the CSR pyramid. It then presents the mixed methods study grounded in Schwartz and Carroll's (2003) revised CSRO model. Finally, implications, limitations and future directions for SME CSR theory and CSRO research in general are highlighted.

\section{THEORETICAL BACKGROUND AND RESEARCH QUESTIONS}

\section{The CSR Pyramid}

Within the kaleidoscope of CSR theories, definitions, approaches and frameworks, there is one concept with enduring success: the CSR pyramid by Carroll (1991) (Calabretta et al., 2011; De Bakker et al., 2005; Ma, 2009). Although the number of citations has more than doubled in the scientific community from 5200 (Carroll, 2016) to over 16000 citations by 2021 (see Google Scholar, 2021), what makes this model of particular relevance id it's contribution to theory building (Jain et al., 2017; Masoud, 2017; Schwartz \& Carroll, 2003; Spence, 2016; Swanson, 1995; Wood, 1991) and entrenchment in business and society educational texts "as a practical tool for analyzing and categorizing responsibility" (Kusyk et al., 2021, p. 1).

Carroll (1979) proposed four CSR dimensions, which he later organized into a normative and prescriptive pyramid with a clear and consistent order of hierarchical priorities and proportionally decreasing weights of importance (4:3:2:1) (Carroll, 1991). It builds on a solid base of economic responsibilities (maximizing profits), adds legal ones (following the law), continues with ethical ones (following prevailing industry norms), and sets the top of the pyramid as discretionary responsibilities (promoting the welfare of society at your own discretion). The pyramid thus assesses the relative emphasis key decision makers place on economic, legal, ethical and/or discretionary responsibilities within their respective enterprises (Acer et al., 2001) and answers the question "What is business responsible for?".

Notably a comprehensive review of the CSR pyramid from 1979 to 2020 (Kusyk et al., 2021) revealed that the CSR pyramid is contextually dependent on environmental, organizational, and individual factors, the influence of which leads to a range of CSR pyramid hierarchies. The review found that only a total of $30 \%$ of the studies supported the original pyramid hierarchy. Secondly, there are calls to study CSR in different contexts (Acer et al., 2001; Spence, 2016), and in particular there is a significant need to study small and medium-sized enterprises (SMEs) (Kusyk et al., 2021). Only two studies (see Burton \& Goldsby, 2009; Klassen, 2001) examine CSR in this organizational context, which is a gross underrepresentation considering that, according to the World Trade Organization, SMEs account for over $90 \%$ of the business population, up to $70 \%$ of employment, and approximately 55\% of global GDP (World Trade Organziation 2016). Third, the review confirmed four CSR dimensions and exposed that there is a persistent trade-off tension between the economic and other responsibilities (Kusyk et al., 2021). These tensions have real implications for CSP and therefore warrant further research into this phenomenon. In light of the growing evidence challenging the CSR pyramid hierarchy (see Kusyk et al., 2021 for a full review), this research aims to further explore whether the CSR hierarchy is accurate in the context of SMEs, with the first research question being as follows.

First research question: does the hierarchy of Carroll's (1991) CSR pyramid hierarchy hold true in the Spanish SME context?

\section{CSRO Domain Portraits}

In practice, enterprises often make trade-offs between their economic, legal, ethical and discretionary/philanthropic responsibilities (Aupperle et al., 1985; Burton \& Goldsby, 2009; Gössling \& Vocht, 2007; Hing, 2001; Schmidt \& Cracau, 2018; W. P. Smith \& Blackburn, 1988; Spence, 2016; van den Heuvel et al., 2014). By doing so, they position themselves in relation to how they will perform on a particular social issue, which is also referred to as CSP (Wood, 1991). To resolve this apparent conflict, Carroll (2016) suggests that an overlap of responsibilities is possible, as in the example of cause-related labeling, which allows for a dual focus on economic and ethical responsibility orientation (Lee et al., 2012). 
In this context, Carroll and Schwartz (2003, p. 519) propose different organizational CSRO portraits of business enterprises based on the relative saliency attached to a particular responsibility: economic, legal, ethical, discretionary, or balanced. They assume that the ideal enterprise will have a balanced approach to CSR. Based on Carroll and Schwartz's (2003,p. 519) set theory approach to CSRO, Table 1 presents how organizations can be categorized and analyzed into their respective CSRO portraits.

\section{TABLE 1 \\ CSRO PORTRAITS}

\section{Corporate Social Responsibility Orientation (CSRO) Ideal Types}

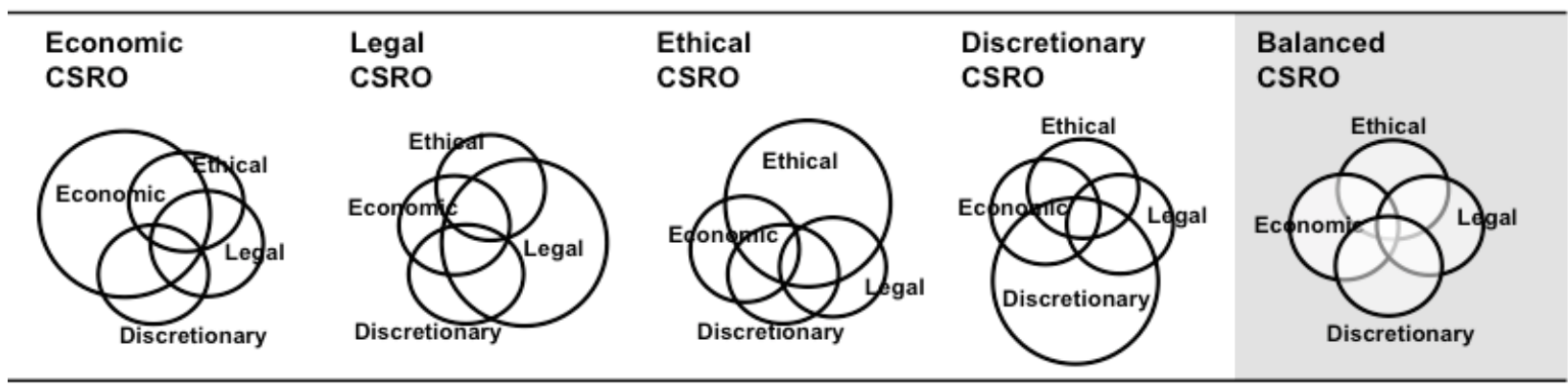

Note. Theoretical grounding for the table includes CSRO (Aupperle,1984), four CSR dimension orientations (Aupperle, 1984; Carroll, 1991) and Venn diagram conceptualization (Schwartz \& Carroll, 2003:519). The balanced CSRO is shaded for emphasis as it is postulated to be the best-practice CSP ideal type CSRO.

\section{Economic Responsibility Orientation (See Table 1, Economic CSRO.)}

Carroll's category of economic responsibility is defined as to "perform in a manner consistent with maximizing earnings per share, being as profitable as possible, maintain a strong competitive position and a high level of operating efficiency." (Carroll, 1991, pp. 40-42). A dominant economic CSRO therefore results in most of the firm's activities having a direct or indirect financial benefit, being illegal (criminal or civil law infractions), or passively complying with the law (Schwartz \& Carroll, 2003). In the CSRO literature, this importance of the domain has been shown to increase firm performance (Maignan \& Ferrell, 2001).

\section{Legal Responsibility Orientation (See Table 1, Legal CSRO.)}

Carroll (1979, p. 500) defines legal responsibility simply as "obeying the law," which is assumed to be a reflection of society's codified ethics. In a company where the legal CSRO is dominant, the majority of the enterprise's activities will be in accordance with a codified legal system.

\section{Ethical Responsibility Orientation (See Table 1, Ethical CSRO.)}

Carroll's ethical responsibility encompasses all activities and practices that are morally expected or prohibited by society beyond codified law (Carroll, 1979). If the majority of corporate activities are based on society's moral expectations or conventional ethical norms, then an ethical CSRO exists.

\section{Discretionary ${ }^{1}$ Responsibility Orientation. (See Table 1, Discretionary CSRO.)}

Discretionary responsibility is defined as engagement that is "purely voluntary and where the decision to undertake it is guided only by a desire to engage in social roles that are not prescribed, that are not required by law, and that are not generally expected of corporations in an ethical sense" (Carroll 1979, p. 500). Thus, a discretionary CSRO exists when the majority of the enterprise activities are based on voluntary positive moral duty initiatives or the promotion of good in society, initiated only by decision makers within the enterprise. 


\section{Balanced Responsibility Orientation (See Table 1, Balanced CSRO.)}

According to Schwartz and Carroll (2003), the four areas of responsibility can be mixed and overlapping. In other words, the majority of the enterprise activities may be simultaneously motivated by economic, legal, ethical, and/or discretionary considerations. A balanced responsibility category is consistent with Carroll's construct of "moral management," which states that profitability can only be achieved in the context of following the law and being sensitive to social norms (Schwartz \& Carroll, 2003). Therefore, theoretically, a balanced orientation between the four ethical categories is plausible and highly desirable as it leads to best practice CSP.

As Schwartz and Carroll (2003, Table) suggest, the pyramid also serves as a basis for developing theories to assess an organization's performance on the four CSR dimensions, also referred to as corporate social performance (CSP) (Swanson, 1995, 1999; Wartick \& Cochran, 1985; Wood, 1991). However, there is scarce empirical research on the CSR pyramid that focuses on how CSRO is related to CSP. Building on Schwartz and Carroll (2003), the second objective of this study is to examine how CSR dimensions differ in high CSP and normal CSP enterprises by asking the second research question: Does a best practice CSP have a balanced CSRO as suggested by Schwartz and Carroll (2003)?

In summary this theoretical enquiry espoused two relevant research questions. It advances our understanding of Carroll's (1991) pyramid on two important fronts: 1) it opens the theoretical lens of CSROs from an overwhelming focus on influencers (Kusyk et al., 2021) to CSRO domains (Schwartz \& Carroll, 2003); 2) it expands the CSRO landscape with an empirical sample of the Spanish SME context around Occupational Health and Safety Issue (Burton \& Goldsby, 2009; Klassen, 2001; Spence, 2016). With this dual aim in mind, this paper now proceeds to the next section, which introduces a multi-method embedded case study design that is particularly suitable for exploratory research into CSR pyramid domains (Miles \& Huberman, 1994).

\section{CASES AND METHODS}

Theoretical grounding requires corresponding appropriate variables in research design (Bacharach, 1989). Therefore, the CSP construct was measured by OHS performance variable, while the CSR construct was measured by the CSRO variable. Construct validity was safeguarded through a data triangulation protocol and control variables in this exploratory multi-method case study. In particular, careful attention was given to three criteria during the design of this study.

1) Design choice for exploratory research. The exploratory nature of the study specifically requires a case study design embedded in multiple methods (Eisenhardt, 1989; Herriott \& Firestone, 1983; Miles \& Huberman, 1994; Yin, 2003). Specifically, this study copies Dentchev's (2004) case analysis tactics and is also consistent with the many voices calling for going beyond quantitative methods to gain a richer understanding of the CSR pyramid phenomenon in general (Schwartz \& Carroll, 2003; Yakovleva, \& Vazquez-Brust, 2012).

2) Selection of CSP variable measure. To minimize a possible value-laden effect on CSP, the study isolates one measurable and highly relevant CSP variable, namely that of occupational health and safety. This choice continues the tradition of employing one social issue as a measure of CSP in the study of CSROs (Gössling, \& Vocht 2007; Hing, 2001; Klassen, 2001; Yakovleva, \& Vazquez-Brust, 2012).

3) Assessment of CSP. Data triangulation of the sources was employed for the selection of theoretical cases. Two literal replication cases were selected for a theoretical "best practice" case CSP (Case 1 and Case 2) and a theoretical normal case CSP (Case 3) for comparison in a similar organizational context (SME, Barcelona, Spain).

\section{Case Study Design}

Selection of Case Studies: Purposeful Sampling

A purposeful theory-based sampling strategy was adopted for a multi-case approach as it is considered more robust than using a single case study to test theory (Herriott \& Firestone, 1983; Eisenhardt, 1989; Yin, 
2003). There were two main concerns that guided the selection of cases. First, identification of theoretical replications of best practice and normal cases for the CSP proxy (see validity). Second, comparability in terms of a narrowly defined organizational context (see control variables) along the same social issue (occupational health and safety). Cross-tabulation of two databases of SME best practice awards from a leading university in Spain (ESADE) and the Spanish National Institute of Health and Safety's narrowed the search to two cases (Case 1 and Case 2). These cases represent the theoretical best practice CSP case. In addition, through the snowball effect (word of mouth technique) a non-award winning CSP SME was identified that did not violate Spanish National Institute health and safety policy and Spanish labor laws. Therefore, this study is made possible through the collaboration of three cases, with two cases serving as theoretical "best practice" CSP case and, a "normal" theoretical case CSP (Case 3).

\section{Control Variables: SME, Sector, Location}

An appropriate case study design requires that cases represent companies facing similar pressures, constraints, and regulations (Hoffman, 2001; Rowley \& Berman, 2000; Swanson, 1995). Therefore, three control variables were deemed appropriate for this study: Company size (SMEs of similar size), industry (cleaning services) and location (Sabadell, same Barcelona Region) for a context of shared ethical social norms and the same dependent variable for CSP (occupational health and safety at work).

\section{Independent Variables: CSR Domains as Units of Analysis}

The dimensions of the CSR pyramid (economic, legal, ethical and discretionary responsibility) were the independent variables (Carroll, 1979, 1991; Schwartz \& Carroll, 2003). These were evaluated through data triangulation (see Appendix A, Table A1 for a sample data source), which consisted of the following: 1) Survey instrument. Remaining close to Carroll's original definition of CSR, Aupperle (1984) developed a survey instrument with 20 questions to measure the four domains of CSR and called it Corporate Social Responsibility Orientation (CSRO). The instrument was condensed by Smith and Blackburn (1988) into a 10-item questionnaire, which also has appropriate psychometric properties (Aupperle, 1991). CSRO assesses the relative importance that key decision makers place on economic, legal, ethical, and/or discretionary responsibilities in their respective enterprises (Acer et al., 2001), and this instrument has successfully measured the dimensions of the CSR pyramid in more than 50 studies over 4 decades (see Kusyk et al., 2021 for a full empirical review). 2) semi-structured interviews lasting approximately 37 hours and 3) thematic analysis of archival data for internal case documents. Both qualitative data sources were subjected to a rigorous case study protocol, which is explained below. The scope of enterprise principles varies depending on the influence of the CSR area in question. In other words, CSP is the observable outcome of a company's behaviour to take responsibility for a range of social issues. (see Table 2 for the coding of CSR domains [Wood 1991, p.710]).

\section{Dependent Variable: Corporate Social Performance (CSP)}

According to Wood (1991, p. 693), CSP is the "degree of to which principles of social responsibility motivate actions on behalf of the company, the degree to which the firm makes use of socially responsive processes, the existence and nature of policies and programs designed to manage the firm's societal relationships and the social impacts (observable outcomes) of the firm's actions, programs, and policies." As mentioned earlier, CSP was used as a proxy for the social issue of occupational health and safety (OHS). OHS was chosen for three important reasons: 1) it is theoretically represented in the CSR literature as the general welfare of employees and is identified as a social issue of high relevance to internal stakeholders (Carroll, 1979); 2) it meets Burke and Logsdon's (1996) criteria for proxy appropriateness because "...it goes beyond legal compliance...is central and specific to the actions of a visible company..." (Dentchev, 2004,p. 401); 3) it is a relevant social issue for practitioners in Europe (European Health and Safety Agency, 2000; European Commission, 2005) and for policy makers in Spain (Spanish Occupational Health Law, 1995) (see Table 2 for coding of CSP [Wood 1991, p. 710]). 


\section{Construct Validity: Selection of Best-Practice CSP Cases}

Data triangulation safeguards construct validity in qualitative data analysis (Miles \& Huberman, 1994; Yin, 2003). The CSP construct's common proxy solution in studies of large companies is to refer to highperforming companies from external CSP rankings such as the Fortune Reputation Survey Gössling \& Vocht, 2007; Griffin \& Mahon, 1997). However, these rankings are not available for SMEs. Therefore, following the tradition of previous SME CSP proxy studies, social issue experts were consulted to identify best practice award-winning companies within the community (Gössling, \& Vocht, 2007). For this study, best practice CSP cases were identified by two separate and independent external expert stakeholder groups (Spanish National Institute for Health and Safety, ESADE Institute for Social Innovation). These experts converged on two cases when nominating them. However, as reputation can sometimes be misleading, and to ensure that the selected cases were truly best in class, the cases were also submitted to a safety climate ${ }^{2}$ survey. The survey results confirmed that each of the two best-practice award-winning cases possessed greatly superior safety climates (Case 1 at $74 \%$, Case 2 at 55\%) than the normal case (Case 3 at 33\%).

\section{External Validity}

External validity is subject to the methodological weakness of not having a sufficient number of cases to generalize to a particular SME population. However, because the case analysis design and protocol meet the most rigorous standards for reliability and construct validity, the study can be used for its intended purpose of generalizing toward the construct which in this case is the CSR domain composition and testing domain interaction (Miles \& Huberman, 1994).

\section{Case Study Protocol}

The case study protocol outlined by Miles and Huberman (1994) was followed for the practitioner expert and business case study interviews, data-analysis, and display. All the interviews were taped, transcribed and coded using ATLAS-ti software.

\section{National Health and Safety Institute Interviews}

To obtain an external expert reference on the CSP proxy of Occupational Health and Safety (OHS), 16 hours of semi-structured interviews were conducted with the Director and Research Manager of the Spanish National Institute for Health and Safety.

\section{Case Study Semi-Structured Interviews}

To gain an understanding of the direction of the field of corporate social responsibility domain orientation, interviews were conducted with managers and employee representatives of the workforce. The fieldwork involved 4 in-depth interviews with managers (including the owner) of the SMEs. This was followed by one supervisor who served as a voice for the entire non-managerial workforce and two nonmanagerial employees. The total number of interviews averaged seven per case or twenty-one in-depth interviews for the entire study. Interviews varied in length and were conducted privately using a recording device, with most ranging from two hours for each executive interviewee to one hour for the non-executive staff. The total duration of all interviews for all case studies was approximately 37 hours. Both management and non-management representatives were interviewed until a saturation point was reached. The interviews with managers tended to take longer as they were more expressive in their responses and knew more details about the various initiatives in their respective companies.

\section{Archival Sources}

In order to access observable outcomes in CSP archival public available data from the company, internet pages were reviewed. The archival sources were particularly important to access the CSP proxy performance. 


\section{Coding and Inter-Coder Check}

Data coding for the interviews regarding the four CSR domains was based on both the definitions provided in the theoretical CSR domain literature (Carroll, 1979; Schwartz \& Carroll, 2003) and the codes previously published by Sonenshein (2006). Wood (1991) classified organizational activities according to institutional, organizational, and individual CSR principles within CSR domains. The secondary data was further classified into the CSR principles identified by Wood (see Principles Model, 1991, p. 702). Semistructured interviews were conducted to triangulate the data for construct validity and these results were further cross-checked with documents and with Aupperle's (1984) CSRO survey instrument. The protocol section clearly outlines all the data collection techniques. Data quality is intact, and the methods prescribed by Miles and Huberman (1994) for data collection, analysis, and presentation were strictly followed. All interviews were recorded, transcribed, and coded using ATLAS-Ti software. Moreover, the agreement between two doctoral students for the qualitative coding scheme is a strong 0.83 .

\section{Analytical Approach to the Interview Data}

Inductive analysis and constant comparison techniques (Glaser \& Strauss, 1967) provided the basis for delineating themes, helped recognize conceptual patterns, and to aggregate dimensions by examining and comparing key constructs and events in the qualitative interview data (Isabella, 1990). First-order codes were based on the "in vivo" language offered by informants (Van Maanen, 1979). After first-order categories were developed, themes emerged between them, which were clustered into theoretically distinguishable groupings or second-order themes. These were combined into overarching dimensions from which the final conclusions for the construct of CSR domain emerged. Table 2 provides an example of the overarching dimensions, second-order themes, language markers for first-order categories, and illustrative examples. The basis of the unit of record was a participant's implicit or explicit reference to one of the four CSR domains, extracted independently for each argument (a discrete reason or justification for supporting an issue) from the personal statements (the context unit). See Table 2 for coding of second-order themes, first-order category markers, and illustrative examples (Wood 1991, p. 710).

TABLE 2

\section{THEORETICALLY GROUNDED SAMPLE LANGUAGE CODING DEFINITIONS AND} ILLUSTRATIVE EXAMPLES*

\begin{tabular}{|c|c|c|c|}
\hline CSR Domains & Second-Order Themes & $\begin{array}{l}\text { First-order } \\
\text { Category } \\
\text { Language } \\
\text { Markers } \\
\end{array}$ & Illustrative Examples \\
\hline $\begin{array}{l}\text { Economic } \\
\text { Responsibility }\end{array}$ & $\begin{array}{l}\text { Explicit: Statements that more } \\
\text { directly mention economic } \\
\text { benefits for the focal } \\
\text { organization. } \\
\text { Implicit: Statements that less } \\
\text { directly mention economic } \\
\text { arguments. The reader must } \\
\text { make a leap (albeit usually a } \\
\text { small one) between the concept } \\
\text { and its benefit on the firm's } \\
\text { economic performance. }\end{array}$ & $\begin{array}{l}\text { sales, market } \\
\text { share, profit, } \\
\text { revenue, } \\
\text { productivity } \\
\text { reputation, } \\
\text { branding, } \\
\text { employee morale. }\end{array}$ & $\begin{array}{l}\text { Doing this "will free up } \\
\text { more time for the employees } \\
\text { to work." } \\
\text { "A better reputation for the } \\
\text { company will give me more } \\
\text { power when I talk to the } \\
\text { policy makers." }\end{array}$ \\
\hline $\begin{array}{l}\text { Legal } \\
\text { Responsibility }\end{array}$ & $\begin{array}{l}\text { Statements that directly } \\
\text { emphasize the law or public } \\
\text { policy and its requirements. }\end{array}$ & law, policy & "This is against the law." \\
\hline
\end{tabular}




\begin{tabular}{|c|c|c|c|}
\hline $\begin{array}{l}\text { Ethical } \\
\text { Responsibility }\end{array}$ & $\begin{array}{l}\text { Statements that directly } \\
\text { emphasize social norms or } \\
\text { industry practice }\end{array}$ & $\begin{array}{l}\text { Social norms, } \\
\text { industry practice, } \\
\text { society } \\
\text { expectations }\end{array}$ & $\begin{array}{l}\text { "Everyone has the ISO } \\
\text { standard to prove that they } \\
\text { run a quality organization." }\end{array}$ \\
\hline \multirow[t]{3}{*}{$\begin{array}{l}\text { Discretionary } \\
\text { Responsibility }\end{array}$} & $\begin{array}{l}\text { Explicit: Statements that } \\
\text { emphasize support for an issue, } \\
\text { independent of its } \\
\text { consequences, the law and/or } \\
\text { social norms. }\end{array}$ & $\begin{array}{l}\text { personal duty, } \\
\text { responsibility, } \\
\text { obligation }\end{array}$ & $\begin{array}{l}\text { "I think we have social } \\
\text { responsibility to help those } \\
\text { immigrants." }\end{array}$ \\
\hline & $\begin{array}{l}\text { Implicit: Statements that less } \\
\text { directly mention an ethical } \\
\text { obligation but are that are laden } \\
\text { with language about moral } \\
\text { values or societal norms and } \\
\text { expectations. }\end{array}$ & $\begin{array}{l}\text { values, } \\
\text { volunteering, } \\
\text { philanthropy }\end{array}$ & "It is the right thing to do." \\
\hline & $\begin{array}{l}\text { Statements that indirectly or } \\
\text { directly emphasize a volunteer } \\
\text { involvement or donation to the } \\
\text { community. }\end{array}$ & & \\
\hline
\end{tabular}

*Intercoder agreement on was an acceptable 0.83 .

\section{Questionnaire Administration}

A questionnaire instrument supplemented the case interview data and observable results (Yin, 1994) to ensure construct validity for both the CSR domains and the CSR performance proxy. A representative sample of internal stakeholders from the three case studies completed the on-site surveys. Of the respondents, 12 were in management positions and 37 were non-management employees. The management instrument tested the CSRO, while employees responded to a two-part instrument consisting of the CSRO and the CSP proxy of OHS climate. For the CSR performance proxy of OHS, the popular safety climate questionnaire developed by Zohar (1980) and later modified by Dedeobbeleer and Beland (1991; cf. Hofmann and Stetzer, 1998) was used with a scale consisting of 9 items. For the CSR construct domains, Aupperle's (1984) revised CSRO survey comprising of 11 groups of 4 statements, was administered in a forced-choice format to minimize social desirability of responses. Respondents were asked to allocate up to 10 points to four statements in each of several sets of statements. Each of the four statements in a set represents a different underlying dimension of Carroll's (1979) four original CSR domains.

\section{Questionnaire Content Validity, Reliability and Social Desirability}

To ensure content validity between the two languages (English and Spanish), a similar translation procedure introduced by Ibrahim and Parsa (2005) was used to translate the questionnaire from English to Spanish. The translated statements were reviewed by a blind review panel of 6 independent Spanishspeaking CSR experts. The order of the statements was maintained from the original version of the questionnaire in order to compare the results for analysis. Aupperle et al. (1985) demonstrated the original reliability of the questionnaire by administering the questionnaire to 158 undergraduate students, calculating Cronbach's alpha for each of the four domains of CSR: economic, .93; legal, .84; ethical, .84; and discretionary, .87. Burton and Hegarty (1999) confirmed an earlier study demonstrating the minimal effect of social desirability on Aupperle's (1984) CSRO instrument.

\section{DISCUSSION WITH RESULTS}

Analytical tactics recommended by Miles and Huberman (1994) were employed to elicit the results for the proposed research questions. The cases were coded using Carroll and Schwartz (2003) who provided a 
theoretical blueprint for CSR domain orientation using Wood's (1991) CSR principles. Initially, the first and second cases were analyzed variable by variable. As patterns and themes began to emerge, the assessment moved to analytic induction logic by making pairwise comparisons between the variables associated with the CSR domains (see Table 2). Thus, in this study, the two best practice cases (Case 1 and Case 2) are considered as one theoretical unit. Most importantly, the literal replication case (Case 3) served as a confirmation/negation of an observed pattern to highlight variances between the results of the best practice and normal CSP cases in their CSR domains. The two research objectives are addressed below.

\section{Implications for the CSR Pyramid Hierarchy}

Does the hierarchy of Carroll's (1991) CSR pyramid apply to the Spanish SME context? Table 3 summarizes the results of the data triangulation to compare the CSRO pyramid given by Carroll (1991) with the research findings for both the theoretical best practice and normal CSP cases. (See Appendix A, Table A1 for the breakdown by data source). Both theoretical cases do not support Carroll's (1991) prescribed pyramid hierarchy: the normal case demonstrates a pyramid hierarchy of economic, ethical, legal and discretionary, and the best practice case not only suggests an alternative hierarchy (economic, legal/ethical, discretionary) but also shows a different emphasis on all areas of responsibility.

TABLE 3

CSR HIERARCHY AND DOMAIN SALIENCE COMPARISON: CARROLL'S (1991) PYRAMID, EMPIRICAL STUDY BEST-PRACTICE AND NORMAL CASE RESULTS

\begin{tabular}{|c|c|c|c|c|c|c|}
\hline & \multicolumn{2}{|c|}{$\frac{\text { Carroll's pyramid }}{\text { (Carroll ,1991) }}$} & \multicolumn{2}{|c|}{$\begin{array}{l}\text { Best-practice case } \\
\text { (multi-case, data-triangul }\end{array}$} & \multicolumn{2}{|c|}{$\frac{\text { Normal practice case }}{\text { empirical results) }}$} \\
\hline $\begin{array}{l}\text { CSR } \\
\text { hierarchy }\end{array}$ & $\begin{array}{l}\text { CSR } \\
\text { domain }\end{array}$ & $\begin{array}{l}\text { Salience } \\
(\%)\end{array}$ & $\begin{array}{l}\text { CSR } \\
\text { domain }\end{array}$ & $\begin{array}{l}\text { Salience } \\
(\%)\end{array}$ & $\begin{array}{l}\text { CSR } \\
\text { domain }\end{array}$ & $\begin{array}{l}\text { Salience } \\
(\%)\end{array}$ \\
\hline 1 & Economic & 40 & Economic & 28 & Economic & 43 \\
\hline 2 & Legal & 30 & Legal/Ethical & 24 & Ethical & 32 \\
\hline 3 & Ethical & 20 & Discretionary & 23 & Legal & 19 \\
\hline 4 & Discretionary & 10 & & & Discretionary & 6 \\
\hline
\end{tabular}

Note. This theoretical construct case table compares Carroll's (1991) pyramid case hierarchy and corresponding prescribed responsibility domain salience with empirical results for best-practice theoretical case and normal theoretical case. Literal case study case percentages for domain salience are the averages of data-triangulation (archival data, thematic analysis, and Aupperle (1984) CSRO questionnaire) where 100\% represents the total salience for each responsibility domain for across-and-within-case comparison purposes.

These findings are consistent with previous sociocultural studies that have found that culturally different regions of the world attach different importance to ethical norms and the law. These meanings shared by members of society are reflected in a variety of CSRO prioritizations and corresponding CSR pyramid hierarchies (N. Ibrahim \& Parsa, 2005; Pinkston \& Carroll, 1996; Ramasamy \& Yeung, 2009; Schmidt \& Cracau, 2018; van den Heuvel et al., 2014). That the hierarchy of the CSR pyramid may be culturally determined, and in particular that in the Spanish context social norms and responsibility considerations take precedence over national laws as is also cited by the INSHT director in one of the interviews:

"In Spain people do not really take the law seriously...take the Spanish Labor Law, we implemented it in 1995 and it took a good 10 years to start being taken into account and we still have a long way to go ... the only way to motivate companies to act is to apply social pressure..." (Spanish National Health and Safety Institute (INSHT, Director) 


\section{Implications for CSRO Theory}

The second research objective was to answer: What is the CSRO of a best practice CSP organization? Based on the findings, a best-practice CSP-CSRO is explained by generalizing back to Schwartz and Carroll's (2003) balanced CSRO hypothesis. Table 2 and Figure 1 demonstrate a relatively balanced CSRO for a best-practice CSP (28\% economic, 24\% ethical and legal, and 23\% discretionary) supporting Schwartz and Carroll's (2003) ideal type with a balanced emphasis on the four CSR dimensions.

\section{FIGURE 1 \\ RADAR GRAPH OF AVERAGE CSR DOMAIN ORIENTATIONS, BY THEORETICAL CASES}

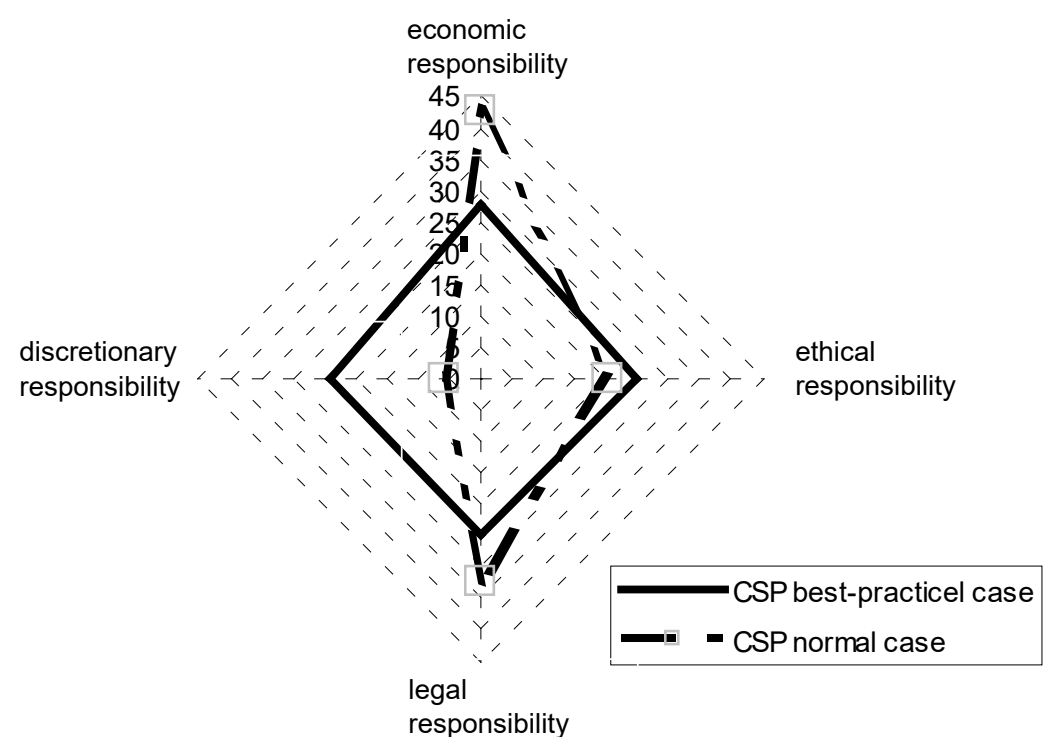

However, although the approach to the CSR dimensions is balanced the economic responsibility forms the basis of the pyramid. In both the best-practice CSP and the normal CSP cases management clearly stated that the economic domain considerations come first:

"...apart from making money we are also working for another future.... The company needs to live: if there is no margin, no workers, no profit the company does not live...." (Best-practice case 1, owner)

At another instance the economic basis was confirmed by the second best-practice case:

“...this company has a social responsibility to make money and to provide employment..." (Best-practice case 2, owner)

A more detailed consideration of the field of economic CSR domain is warranted because Wood's (1991) CSR principles help explain the difference between best practice and normal CSP CSR. Objectively, economic profit is a necessary precondition for a for-profit business function and institutional legitimacy (Wood, 1991). Subjectively, the economic domain extends towards organizational and individual CSR principles (Wood, 1991). The difference between a normal and a best practice case becomes evident beyond the principle of social legitimacy:

"The bottom line is that we are a company that needs to make a profit. Need to survive. But profit is not our primary and priority goal. ...." (Best-practice case 1, owner) 
The two key differences between the best-practice case and the theoretical normal case lie in the relative emphasis placed on economic and discretionary responsibility. First, these results suggest that a balanced presence of the discretionary responsibility domain relative to the other domains is the key indicator of a best practice case CSP as theorized by Schwartz and Carroll (2003). Second, a near absence of the area of discretionary responsibility and a strong tendency towards the economic area suggests a CSP normal case. Confirming Wood's (1991) assertion that only a best practice case CSRO takes into account managerial discretion. This provides a new insight that the domain of discretionary responsibility is a distinguishing feature between best-practice and normal-practice corporate performance. Thus, the three-domain approach (Schwartz \& Carroll, 2003) is not sufficient to distinguish between different types of CSROs, and this study confirms the necessity of the discretionary domain for identifying CSROs (Aupperlee, 1984), while at the same time the study shows that the discretionary component of the pyramid is dependent on CSROs.

\section{Implications for SME Practitioners, Policy Makers, Curriculum Design}

This study may be of particular interest to Spanish policy makers who wish to improve the normal CSP for SMEs. As mentioned above, contrary to the original CSRO hierarchy (economic, legal, ethical, discretionary), the Spanish SME has the following CSROs: economic, ethical, legal and discretionary. Policy makers need to take into account that the CSRO is contextual and has a clear economic basis and is strongly influenced by ethical norms. Although the economic priority is the same for all SMEs, it is given very different degrees of importance. The findings confirm previous work that economic responsibility is indeed the most important responsibility of an SME (Burton \& Goldsby, 2009). However, contrary to (Buchholtz et al., 1999), SMEs are not prevented by limited resources (due to their relatively small size) from engaging with discretionary activity in society. This research shows that in Spanish SMEs CSRO ethical norms are a greater trigger than legislation in the Spanish context. Therefore, law has limited potential to regulate CSR. If SMEs are to engage in social issues, the momentum must be strengthened by activating levers in industry and society to improve CSP. As our study of Occupational Health and Safety (OHS) demonstrates, more laws will not improve overall OHS performance because SMEs within an industry look to each other for ethical standards of conduct. Policymakers need to find creative ways to raise social norms by rewarding improved standards, for example, through public recognition and promotion of best practice cases CSP.

Furthermore, this research underscores the importance of ethical leadership for practitioners. The second finding of this study is that exemplary companies (CSP), as postulated by Schwartz and Carroll (2003) adopt a balanced approach to CSR domain responsibility. This points to the role of discretionary responsibility in building best practice enterprises and leads to two important considerations: Ethical leadership and the SME context. First, the findings suggest that society needs ethical leaders who make discretionary decisions to advance CSP if they are to have a high CSP company. This supports Wood's (1991, p. 699) assertion that "...a company's social responsibilities are not by some abstract organizational actor, they are met by individual human actors who constantly make decisions...some minor and some others of great consequence." Secondly, the motivations for owning a business can range from simply making money to other passions (Burton \& Goldsby, 2009), and in the SME context, individual actors have more autonomy and power due to the absence of systems and structures (Spence, 1999).

Furthermore, in terms of inclusive curriculum design, a balanced approach to CSR teaching is needed, ranging from entrepreneurial SMEs to large organizations, and distinguishing between individual ethical decision-making models and institutionalized CSR strategies.

\section{Limitations}

The qualitative design of the exploratory study was appropriate for testing theory propositions (Miles \& Huberman, 1994; Eisenhardt, 1989). However, the results must be interpreted with caution because they cannot be generalized to a population due to the limited number of cases employed and are representative only of the cases and theory used in this study. Furthermore, the first and most important limitation is the nature of the study, namely the pre-existing conceptualizations of CSR as proposed by Carroll $(1979,1991)$ in Aupperle's (1984) study. To compensate for this limitation, the qualitative interviews and thematic 
analysis allowed for a free exploration of how the various internal social actors of SMEs define CSR in general and how they identify significant CSR enterprise activities in particular.

\section{Future Research Directions}

CSRO is ripe for further SME theory testing and development (Jenkins, 2014; Paul et al., 2019; Spence 2016). The size of an organization can affect access to resources and ownership structure, which influence control over decision making and the exercise of social responsibility (Klassen 2001; Kusyk and Lozano, 2007; Spence, 2016). This seminal study has shown that the hierarchy of the Spanish CSR pyramid for SMEs differs from the pyramid originally proposed by Carroll (1991). Future research could build on Schwartz and Carroll's (2003) hypothesis that a balanced CSRO leads to a best practice company CSP. Taking this work further would raise the question: Is engagement in discretionary responsibility a predictor of CSP? In particular, it would be interesting to further investigate the importance of discretionary responsibility for CSROs and CSP in different industries and in relation to a range of social issues.

Perceptions of responsibility can be influenced by a person's social position or role in a social context (such as occupation, position in the organizational hierarchy, and perspective of the social actor) (Smith et al., 2001). Research on the influence of social role on CSRO has found that there are differences in CSRO prioritization between CEOs and/or internal and external board members (Ibrahim \& Angelidis, 1995; O'Neill et al., 1989), students, and business managers (Ibrahim \& Angelidis, 1992), and that position in the organizational hierarchy influences CSRO (Angelidis et al., 2008; Gössling \& Vocht, 2007). The effect of leadership position in the organizational hierarchy in relation to ownership has not yet been investigated. In the context of SME CSROs, it would be interesting to investigate the role of leadership position in the organization in shaping CSROs. In particular, it would also be informative to examine the extent to which an owner's personal CSRO influences the overall CSRO of the firm.

Although CSRO answers the question "What are organizations responsible for?" the model neglects social actors or fails to ask the question "To whom is business responsible?" (Maignan \& Ferrell, 2003). This critique was reflected in the stakeholder perspective of CSR (Maignan \& Ferrell, 2003) and, more recently, in research on corporate social orientation (Jain et al., 2017). In particular, the work of Jain et al. (2017) is promising in terms of linking CSROs to public policy and stakeholder engagement, and in terms of linking CSROs to CSOs.

In summary, future research should aim to further expand our knowledge of CSROs in the SME context. In particular, this paper proposes to focus on the discretionary dimension as an indicator of social performance and to investigate the impact of individual social role and ownership on organizational CSRO.

\section{CONCLUSION}

The CSR pyramid (Carroll, 1991) plays an essential role in the business and society field, and research on it is incomplete if it ignores the full gambit of organizational contexts. By focusing on small business, this study makes a dual contribution to the growing body of CSRO theorizing in a previously underresearched empirical setting. First, it shifts the lens away from the hegemony of studying large firms and adds another piece of knowledge to the puzzle of the composition of the CSR pyramid in a previously unexplored context of Spanish SMEs. The findings of this research suggest that Carroll's (1991) hierarchy of the CSR pyramid does not stand up to empirical investigation, and this research joins the numerous voices of previous studies calling for a conceptual shift from the proposed fixed one-size-fits-all CSR hierarchy (economic, legal, ethical, discretionary) to a contextual pyramid. Secondly, this study contributes to the discussion on balancing CSR dimensions by providing empirical support for Schwartz \& Carroll's (2003) ideal balanced CSRO model, while reinstituting the discretionary responsibility domain. Combining these findings with the CSRO literature sends an important message of hope that best practice CSP has been identified, but improvements need to be made on several fronts, not least via a re-examination of organizational leadership commitment to 'discretionary' CSR. 


\section{ENDNOTES}

1. Carroll $(1999,2016)$ suggested that "discretionary" responsibility was narrowly interpreted as "philanthropy" in practice. For the purposes of this study, and to maintain consistency with previous research, as well as, some current work that still adheres to the term "discretionary" (see Table 1). In this study, the original wide domain definition of "discretionary" responsibility is retained.

2. Safety Climate is defined as "incumbent's perceptions of the events, practices, and procedures and the kinds of behaviors that get rewarded, supported, and expected in a setting" (Schneider, 1990, p.384). Measuring safety climate is an appropriate indicator of the company's overall CSP on the social issue OHS. Safety climate was measured by two factors: Management commitment to safety in terms of management safety attitudes and practices and employee participation in safety standards (Dedobbeleer \& Béland, 1991; Hofman \& Stetzer, 1998; Zohar, 1980).

\section{REFERENCES}

Acer, W., Aupperle, K.E., \& Lowy, R.M. (2001). An empirical exploration of measures of social responsibility across the spectrum of organizational types. The International Journal of Organizational Analysis, 9, 26-57.

Angelidis, J.P., Tobin, P.J., Massetti, B.L., \& Magee-Egan, P. (2008). Does Corporate Social Responsibility Orientation Vary by Position in the Organizational Hierarchy? Review of Business, 28(3), 23-32. Retrieved from http://cowles-

proxy.drake.edu/login?url=http://search.ebscohost.com/login.aspx?direct=true \&db=bsh\&AN=34 $757417 \&$ site $=$ ehost-live

Aupperle, K.E. (1984). An empirical measure of corporate social orientation. In L.E. Preston (Ed.), Research in corporate social performance and policy (pp. 27-54). JAI Press.

Aupperle, K.E., Carroll, A.B., \& Hatfield, J.D. (1985). An empirical examination of the relationship between corporate social responsibilty and profitability. Academy of Management Review, 28(2), 446-463.

Bacharach, S. (1989). Organizational theories: Some criteria for evaluation. Academy of Management Review, 14(4), 496-515. https://doi.org/10.2307/258555

Buchholtz, A.K., Amason, A.C., \& Rutherford, M.A. (1999). Beyond Resources. Business \& Society, 38(2), 167-187. https://doi.org/10.1177/000765039903800203

Burke, L., \& Logsdon, J.M. (1996). How Corporate Social Responsibility Pays Off. Long Range Planning, 29(4), 495-502. https://doi.org/10.1016/0024-6301(96)00041-6

Burton, B.K., \& Goldsby, M. (2009). Corporate Social Responsibility Orientation, Goals, and Behavior. Business \& Society, 48(1), 88-104. https://doi.org/10.1177/0007650307305367

Burton, B.K., \& Hegarty, W.H. (1999). Some determinants of student corporate social responsibility orientation. Business and Society, 38(2), 188-205. https://doi.org/10.1177/000765039903800204

Calabretta, G., Durisin, B., \& Ogliengo, M. (2011). Uncovering the Intellectual Structure of Research in Business Ethics: A Journey Through the History, the Classics, and the Pillars of Journal of Business Ethics. Journal of Business Ethics, 104(4), 499-524. https://doi.org/10.1007/s10551011-0924-8

Carroll, A.B. (1979). A three-dimensional conceptual model of corporate performance. Corporate Social Responsibility, 4(4), 497-505. https://doi.org/10.5465/amr.1979.4498296

Carroll, A.B. (1991, July/August). The pyramid of corporate social responsibility: Toward the moral management of organizational stakeholders. Business Horizons, pp. 39-48. Retrieved from http://www.ncbi.nlm.nih.gov/pubmed/5536871

Carroll, A.B. (2016). Carroll's pyramid of CSR: taking another look. International Journal of Corporate Social Responsibility, 1(3), 1-8. https://doi.org/10.1186/s40991-016-0004-6

Carroll, A.B., \& Shabana, K.M. (2010). The business case for corporate social responsibility: A review of concepts, research and practice. International Journal of Management Reviews, 12(1), 85-105. https://doi.org/10.1111/j.1468-2370.2009.00275.x 
De Bakker, F.G.A., Groenewegen, P., \& Den Hond, F. (2005). A bibliometric analysis of 30 years of research and theory on corporate social responsibility and corporate social performance. Business and Society, 44(3), 283-317. https://doi.org/10.1177/0007650305278086

Dedobbeleer, N., \& Béland, F. (1991). A safety climate measure for construction sites. Journal of Safety Research, 22(2), 97-103. https://doi.org/10.1016/0022-4375(91)90017-P

Dentchev, N.A. (2004). Corporate social performance as a business strategy. Journal of Business Ethics, 55(4), 397-412. https://doi.org/10.1007/s10551-004-1348-5

Edmondson, V.C., \& Carroll, A.B. (1999). Giving back: An examination of the philanthropic motivations, orientations and activities of large black-owned businesses. Journal of Business Ethics, 19(2), 171-179. https://doi.org/10.1023/A:1005993925597

Eisenhardt, K. (1989). Building theories from case study research. Academy of Management Review, 14(4), 532-550. https://doi.org/10.1016/s0140-6736(16)30010-1

Glaser, B., \& Strauss, A. (1967). Discovering grounded theory. Aldine.

Google Scholar. (2021). “Corporate Social Responsibilty Pyramid” Citation Count.

Gössling, T., \& Vocht, C. (2007). Social role conceptions and CSR policy success. Journal of Business Ethics, 74(4), 363-372. https://doi.org/10.1007/s10551-007-9512-3

Griffin, J.J., \& Mahon, J.F. (1997). The corporate social performance and corporate financial performance debate: Twenty-five years of incomparable research. Business and Society, 36(1), 5-31. https://doi.org/10.1177/000765039703600102

Herriott, R., \& Firestone, W. (1983). Multisite qualitative policy research: Optimizing description and generalizability. Educational Researcher, 12, 14-19.

Hing, N. (2001). Changing the odds: A study of corporate social principles and practices in addressing problem gambling. Journal of Business Ethics, 33(2), 115-144. https://doi.org/10.1023/A:1017527429283

Hoffman, A.J. (2001). Linking organizational and field-level analyses: The Diffusion of corporate environmental practice. Organization and Environment, 14(2), 133-156. https://doi.org/10.1177/1086026601142001

Hofman, D., \& Stetzer, A. (1998). The role of safety climate and communication in accident interpretation: Implications for learning from negative events. Academy of Management Journal, 41(6), 644-657.

Ibrahim, N.A., \& Angelidis, J.P. (1995). The corporate social responsiveness orientation of board members: Are there differences between inside and outside directors? Journal of Business Ethics, 14(5), 405-410. https://doi.org/10.1007/BF00872102

Ibrahim, N., \& Angelidis, J. (1992). Corporate Social Responsiblity: A comparative analysis of perceptions of top executives and business students. The Mid-Atlantic Journal of Business, 29(3), 303-313. http://dx.doi.org/10.1016/j.jaci.2012.05.050

Ibrahim, N., \& Parsa, F. (2005). Corporate Social Responsiveness Orientation: Are There Differences between U.S. and French Managers? Review of Business, $26(1), 27$.

Isabella, L.A. (1990). Evolving interpretations as change unfolds: How managers construe key organizational events. Academy of Management Journal, 33(1), 7-41.

Jain, T., Aguilera, R.V., \& Jamali, D. (2017). Corporate Stakeholder Orientation in an Emerging Country Context: A Longitudinal Cross Industry Analysis. Journal of Business Ethics, 143(4), 701-719. https://doi.org/10.1007/s10551-016-3074-1

Klassen, R.D. (2001). Plant-level environmental management orientation: The influence of management views and plant characteristics. Production and Operations Management, 10(3), 257-275. https://doi.org/10.1111/j.1937-5956.2001.tb00374.x

Kusyk, S., Shwartz, M.S., \& Lozano, J.M. (2021, July). Excavating the CSR Pyramid: A Review, Assessment, and Normative Treasure. Journal of Business Ethics, Revise and Resubmit.

L'Etang, J. (1994). Public relations and corporate social responsibility: Some issues arising. Journal of Business Research, 13(2), 111-123. 
Lee, Y.J., Haley, E., \& Mark, A.Y. (2012). The Effects of Corporate Social Responsibility Orientation on the Consumer's Perception of Advertisers' Intention. Journal of Current Issues and Research in Advertising, 33(2), 192-209. https://doi.org/10.1080/10641734.2012.700792

Ma, Z. (2009). The status of contemporary business ethics research: Present and future. Journal of Business Ethics, 90(SUPPL 3), 255-265. https://doi.org/10.1007/s10551-010-0420-6

Maignan, I., \& Ferrell, O.C. (2001). Antecedents and benefits of corporate citizenship: An investigation of French businesses. Journal of Business Research, 51(1), 37-51. https://doi.org/10.1016/S01482963(99)00042-9

Maignan, I., \& Ferrell, O.C. (2003). Nature of corporate responsibilities perspectives from American, French, and German consumers. Journal of Business Research, 56(1), 55-67. https://doi.org/10.1016/S0148-2963(01)00222-3

Masoud, N. (2017). How to win the battle of ideas in corporate social responsibility: The International Pyramid Model of CSR. International Journal of Corporate Social Responsibility, 2(1). https://doi.org/10.1186/s40991-017-0015-y

Miles, R., \& Huberman, A. (1994). An expanded sourcebook: Qualitative data analysis. Sage Publications.

O’Neill, H.M., Saunders, C.B., \& McCarthy, A.D. (1989). Board members, corporate social responsiveness and profitability: Are tradeoffs necessary? Journal of Business Ethics, 8(5), 353357. https://doi.org/10.1007/BF00381726

Paul, E., Gibson, J., \& Smith, P. (2019). Influential Article Review - The Global Pyramid Model of CSR What is the Best Way to Perform Corporate Social Responsibility. Journal of Leadership, Accountability and Ethics, 16(6), 1-27.

Pinkston, T.S., \& Carroll, A.B. (1996). A retrospective examination of CSR orientations: Have they changed? Journal of Business Ethics, 15(2), 199-206. https://doi.org/10.1007/BF00705587

Ramasamy, B., \& Yeung, M. (2009). Chinese consumers' perception of corporate social responsibility (CSR). Journal of Business Ethics, 88(SUPPL. 1), 119-132. https://doi.org/10.1007/s10551-0089825-X

Rowley, T., \& Berman, S. (2000). A Brand New Brand of Corporate Social Performance. Business \& Society, 39(4), 397-418. https://doi.org/10.1177/000765030003900404

Schmidt, M.A., \& Cracau, D. (2018). A cross-country comparison of the corporate social responsibility orientation in Germany and Qatar: An empirical study among business students. Business and Professional Ethics Journal, 37(1), 67-104. https://doi.org/10.5840/bpej201712866

Schwartz, M.S., \& Carroll, A.B. (2003). Corporate Social Responsiblity: A Three-domain approach. Business Ethics Quarterly, 13(4), 503-530.

Smith, W.J., Wokutch, R.E., Harrington, K.V., \& Dennis, B.S. (2001). An Examination of the Influence of Diversity and Stakeholder Role on Corporate Social Orientation. Business \& Society, 40(3), 266-294. https://doi.org/10.1177/000765030104000303

Smith, W.P., \& Blackburn, R. (1988). Corporate social responsibility: A psychometric examination of a management instrument. Proceedings of the Southern Management Association, pp. 293-295.

Spence, L.J. (2016). Small Business Social Responsibility: Expanding Core CSR Theory. Business and Society, 55(1), 23-55. https://doi.org/10.1177/0007650314523256

Swanson, D.L. (1995). Addressing a Theoretical Problem by Reorienting the Corporate Social Performance Model. Academy of Management Review, 20(1), 43-64. https://doi.org/10.5465/amr.1995.9503271990

Swanson, D.L. (1999). Toward an Integrative Theory of Business and Society: A Research Strategy for Corporate Social Performance. The Academy of Management Review, 24(3), 506. https://doi.org/10.2307/259139

van den Heuvel, G., Soeters, J., \& Gössling, T. (2014). Global Business, Global Responsibilities: Corporate Social Responsibility Orientations Within a Multinational Bank. Business and Society, 53(3), 378-413. https://doi.org/10.1177/0007650311424724 
Van Maanen, J. (1979). The first fact of fiction in organizational ethnography. Administrative Science Quarterly, 24(4), 539-550.

Visser, W. (2006). Revisiting Carroll 's CSR pyramid:An African Perspective. In A. Crane \& D. Matten (Eds.), Corporate Social Responsibility: Three Volume Set (pp. 195-212). Sage. Retrieved from http://books.google.com/books?hl=en\&amp;lr=\&amp;id=8Z9MnR1N7LgC\&amp;oi=fnd\&amp;p $\mathrm{g}=\mathrm{PA} 29 \& \mathrm{amp} ; \mathrm{dq}=$ Revisiting + Carroll? $\mathrm{s}+\mathrm{CSR}+$ pyramid\&amp;ots=rl6jZENdnw\&amp;sig=osBts 6BztNtgSzbHK 8s1sYPZ4

Wartick, S.L., \& Cochran, P.L. (1985). The Evolution of the Corporate Social Performance Model. Academy of Management Review, 10(4), 758-769. https://doi.org/10.5465/amr.1985.4279099

Wood, D.J. (1991). Subdirekte Produkte und konjunkte Summen. Academy of Management Review, 16(4), 691-718.

World Trade Organization. (2016). World trade report 2016. Levelling the trading field for SMEs. Retrieved from https://www.wto.org/english/res_e/publications_e/wtr16_e.htm

Yin, R. (2003). Case study research: Design and methods (2nd ed.). Sage.

Zohar, D. (1980). Safety climate in industrial organizations: Theoretical and applied implications. Journal of Applied Psychology, 65(1), 96-102. https://doi.org/10.1037/0021-9010.65.1.96

\section{APPENDIX: SAMPLE DATA SOURCE}

TABLE A1

CSR DOMAIN ORIENTATION, BY CASE AND DATA SOURCE (\%)

\begin{tabular}{lllll}
\hline Data Source/Case & \multicolumn{3}{l}{ CSR Orientation (\%) } & \\
& Economic & Legal & Ethical & Discretionary \\
\hline Best-practice CSP cases, archival data & 30 & 21 & 26 & 23 \\
Best-practice CSP cases, thematic analysis & 26 & 20 & 25 & 33 \\
Best-practice CSP cases, CSO survey instrument & 27 & 33 & 24 & 16 \\
Averages: Best-practice CSP cases & $\mathbf{2 7}$ & $\mathbf{2 5}$ & $\mathbf{2 5}$ & $\mathbf{2 4}$ \\
Normal CSP cases, archival data & 40 & 20 & 40 & 0 \\
Normal CSP cases, thematic analysis & 53 & 20 & 24 & 6 \\
Normal CSP cases, CSO survey instrument & 35 & 21 & 33 & 11 \\
Averages: Normal CSP cases & $\mathbf{4 3}$ & $\mathbf{2 0}$ & $\mathbf{3 2}$ & $\mathbf{6}$ \\
\hline
\end{tabular}

Note: All results displayed are converted into percentiles, where $100 \%$ represents the total amount for each category, for across-and-within case comparison purposes. The average of Case 1 and Case 2 is the theoretical unit called "best-practice" CSP case.

*Abbreviations: $\mathrm{CSP}=$ Corporate Social Performance, $\mathrm{CSR}=$ Corporate Social Responsibility, $\mathrm{CSRO}=\mathrm{CSR}$ orientation 